\title{
Prolapse of a large pedunculated uterine myoma.
}

Ioannis Papapanagiotou ${ }^{1}$, Sofoklis Stavros ${ }^{1}$, Dimitrios Vlachos ${ }^{1}$, Kyriaki Migklis ${ }^{1}$, Konstantina Papadatou ${ }^{1}$, Dimitrios Papageorgiou ${ }^{1}$, Ekaterini Domali ${ }^{2}$, Peter Drakakis ${ }^{1}$, Alexandros Rodolakis ${ }^{2}$, and Nikolaos Thomakos ${ }^{1}$

${ }^{1}$ General Hospital Alexandra

${ }^{2}$ National and Kapodistrian University of Athens

March 30, 2021

\begin{abstract}
We report a rare case of a large prolapsed pedunculated uterine myoma measuring $15 \mathrm{~cm}$ in its greater diameter. In order to make a surgical procedure safe and feasible, appropriate clinical predictors should be taken into account and pre- and intraoperative preparations be available to the surgeon's armamentarium.
\end{abstract}

\section{Hosted file}

Main document.pdf available at https://authorea.com/users/396841/articles/516040-prolapse-ofa-large-pedunculated-uterine-myoma

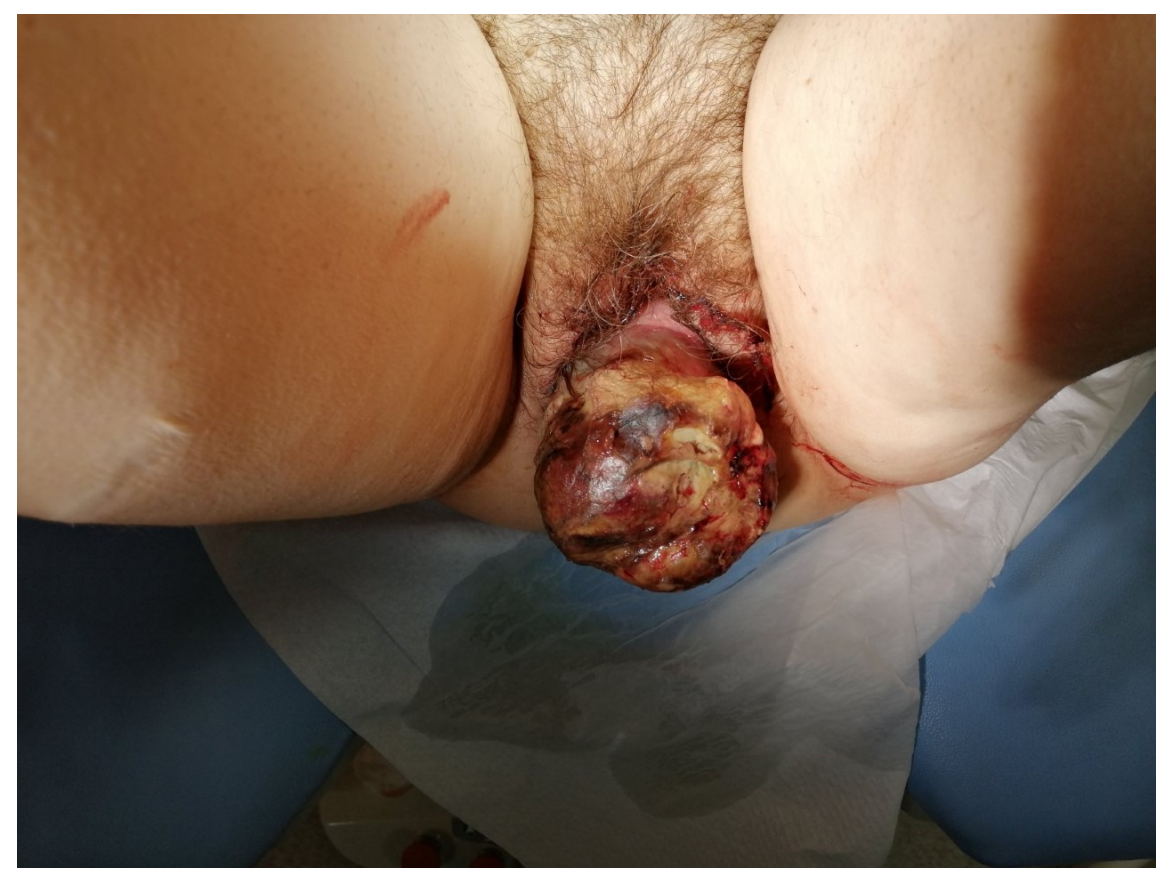




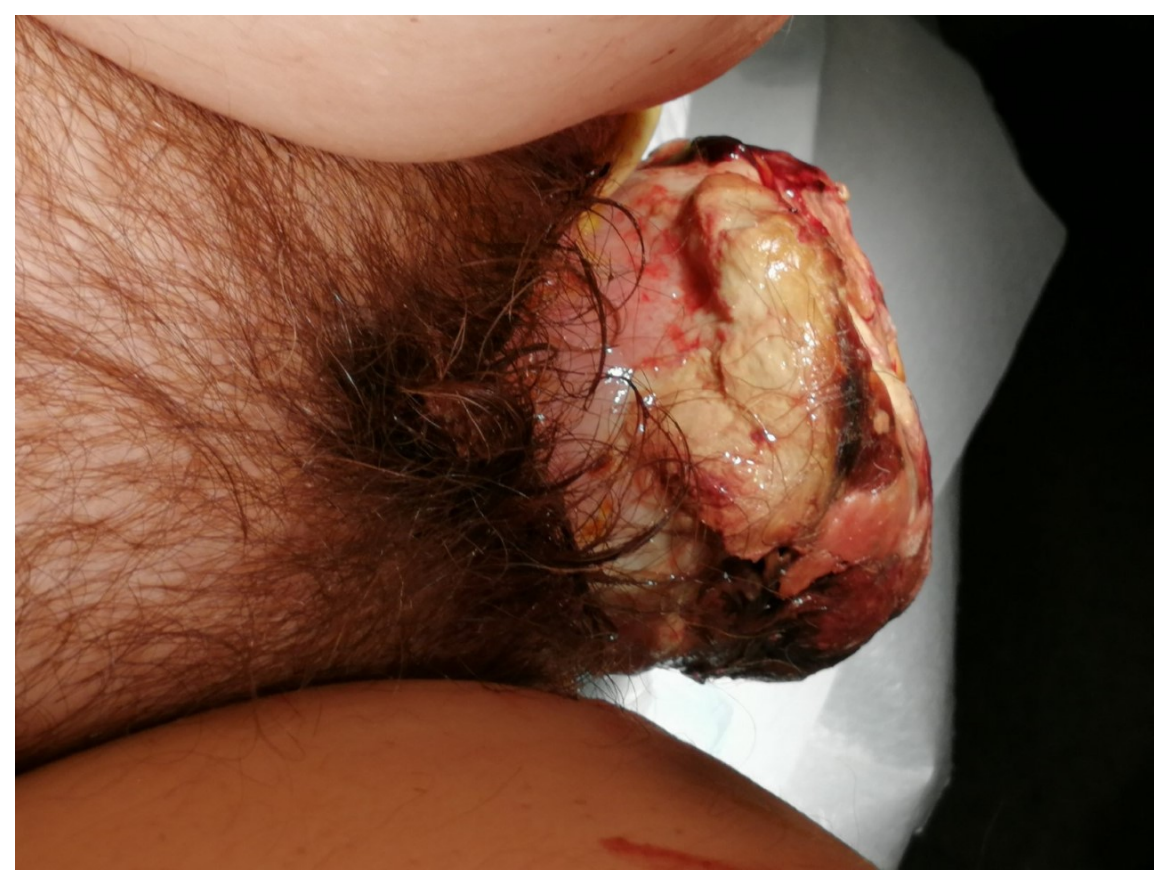

